\title{
Suppressor of cytokine signaling 1 blocks mitosis in human melanoma cells
}

\author{
Verónica Parrillas • Laura Martínez-Muñoz • Borja L. Holgado • \\ Amit Kumar · Graciela Cascio · Pilar Lucas • José Miguel Rodríguez-Frade • \\ Marcos Malumbres • Ana C. Carrera - Karel HM van Wely • \\ Mario Mellado
}

Received: 30 March 2012/Revised: 6 August 2012/Accepted: 20 August 2012/Published online: 23 September 2012

(C) Springer Basel AG 2012

\begin{abstract}
Hypermethylation of SOCS genes is associated with many human cancers, suggesting a role as tumor suppressors. As adaptor molecules for ubiquitin ligases, SOCS proteins modulate turnover of numerous target proteins. Few SOCS targets identified so far have a direct role in cell cycle progression; the mechanism by which SOCS regulate the cell cycle thus remains largely unknown. Here we show that SOCS1 overexpression
\end{abstract}

Electronic supplementary material The online version of this article (doi:10.1007/s00018-012-1145-8) contains supplementary material, which is available to authorized users.

V. Parrillas · L. Martínez-Muñoz · B. L. Holgado · G. Cascio · P. Lucas · J. M. Rodríguez-Frade · M. Mellado ( $\square)$

Chemokines Group, Department of Immunology and Oncology, Centro Nacional de Biotecnología/CSIC, Darwin 3,

Cantoblanco, 28049 Madrid, Spain

e-mail:mmellado@cnb.csic.es

A. Kumar · A. C. Carrera

PI3K Group, Department of Immunology and Oncology, Centro

Nacional de Biotecnología/CSIC, 28049 Madrid, Spain

M. Malumbres

Cell Division and Cancer Group, Spanish National Cancer

Research Center (CNIO), 28029 Madrid, Spain

K. H. van Wely $(\square)$

Genetic Instability Group, Department of Immunology and

Oncology, Centro Nacional de Biotecnología/CSIC, 28049

Madrid, Spain

e-mail: kvanwely@cnb.csic.es

Present Address:

A. Kumar

Fondazione Istituto FIRC di Oncologia Molecolare (IFOM),

20139 Milan, Italy inhibits in vitro and in vivo expansion of human melanoma cells, and that SOCS1 associates specifically with Cdh1, triggering its degradation by the proteasome. Cells therefore show a G1/S transition defect, as well as a secondary blockade in mitosis and accumulation of cells in metaphase. SOCS1 expression correlated with a reduction in cyclin $\mathrm{D} / \mathrm{E}$ levels and an increase in the tumor suppressor p19, as well as the CDK inhibitor p53, explaining the G1/S transition defect. As a result of Cdh1 degradation, SOCS1-expressing cells accumulated cyclin B1 and securin, as well as apparently inactive Cdc20, in mitosis. Levels of the late mitotic Cdh1 substrate Aurora A did not change. These observations comprise a hitherto unreported mechanism of SOCS1 tumor suppression, suggesting this molecule as a candidate for the design of new therapeutic strategies for human melanoma.

Keywords SOCS1 Cdh1 Cell cycle ·

Tumor suppressor
Abbreviations
APC/C Anaphase-promoting complex/cyclosome
BrdU 5-bromo-2'-deoxyuridine
CDK Cyclin-dependent kinase
CFP Cyan fluorescent protein
FRET Fluorescence resonance energy transfer
IRS Insulin receptor substrate 1
JAK2 Janus kinase 2
MAD2 Mitotic arrest deficient 2
Mdm2 Murine double minute 2
$\mathrm{SH} 2 \quad$ Src homology 2
SOCS Suppressor of cytokine signaling
STAT Signal transducer and activator of transcription
YFP Yellow fluorescent protein 


\section{Introduction}

The frequent reduction of SOCS gene expression in human cancers indicates that SOCS proteins have a role as tumor suppressors. Decreased SOCS gene expression due to promoter methylation has been observed in advanced human cancers including melanoma [1-7]. In agreement with a proposed role in tumor suppression, SOCS1-deficient mice show myeloproliferative disorders and lymphomas [8-10]. In addition, SOCS1-deficient fibroblasts are susceptible to transformation by CBL and TEL-JAK2 oncogenes [11], whereas SOCS1 overexpression in tumor cells blocks proliferation [6, 11]. SOCS deficiency correlates with enhanced invasion and angiogenesis of melanoma cells [12]. Treatment with an analog of the SOCS1 protein SH2 domain has antiproliferative effects on prostate tumor cells; although the mechanism is still unclear, it appears to involve reduced cyclin levels and interference with cell cycle progression [13].

SOCS proteins direct the turnover of cellular targets through the formation of a complex with the ElonginCullin E3 ligase complex $[14,15]$. In this way, SOCS modulates the ubiquitination of a variety of proteins, which are subsequently recognized by the proteasome and degraded. Proteins whose ubiquitination is modulated by SOCS include JAK2 [16], the insulin signaling intermediates IRS1 and IRS2 [17], the NF-kappaB subunit RelA [18], and focal adhesion kinase [19], among others. Although some studies describe that some SOCS targets, including JAK/STAT, are involved in signaling events that promote proliferation (for example, the activation of cyclin D promoters $[20,21])$, others report suppression of proliferation by the same pathways [22, 23]. Through a mechanism involving the $\mathrm{SH} 2$ domain and $\mathrm{C}$ terminal SOCS box region, SOCS1 can induce p53-dependent senescence in fibroblasts. In addition, SOCS1 is required for the p53-dependent response to constitutively active STAT5A [24].

The wide variety of tumors that show SOCS gene promoter methylation suggests that, in addition to its effect on upstream signaling pathways, SOCS modulates the cell cycle at its core. Given the importance of ubiquitination in the cell cycle and the potential role of SOCS as an adaptor for ubiquitin ligases, SOCS proteins might target one or more key regulators of cell cycle progression. The mammalian cell cycle is regulated by a group of protein complexes, each composed of a catalytic subunit termed cyclin-dependent kinase (CDK) and a regulatory subunit, cyclin. The CDK phosphorylates key regulators of cell cycle progression only when associated with a cyclin, which are cell cycle phase-specific $[25,26]$.
Phosphorylation of substrates by CDK is regulated through its association with one cyclin molecule per kinase subunit [27]; CDK complexes are inactivated through the ubiquitination and proteolytic degradation of the cyclin subunit [28, 29]. Ubiquitination of cyclins and other relevant cell cycle proteins, and thereby the coordination of cell cycle progression, depends on the anaphase-promoting complex/ cyclosome (APC/C). The APC/C is a large ubiquitin E3 ligase complex coordinated by two homologous mitotic coactivators, Cdc20 and Cdh1 [30]. Substrate selection by $\mathrm{Cdc} 20$ and $\mathrm{Cdh} 1$ results in the sequential degradation of individual target proteins in each step of mitosis; whereas APC/C-Cdc20 targets the anaphase inhibitor securin and initiates chromosome separation, APC/C-Cdh1 promotes degradation of spindle proteins such as Aurora kinases and Cdc20 itself [31]. Because of its role in the metaphaseanaphase transition, APC/C-Cdc20 activity is controlled through the spindle assembly checkpoint [32]. Direct interaction of the mitotic checkpoint complex and the activity of CDK1 inhibit APC/C-Cdc20 as long as the spindle checkpoint is engaged [33-35]. Only a few early APC/C substrates, for example NEK2, are degraded before spindle checkpoint inactivation. These substrates seem to be ubiquitinated through direct interaction with the APC/C core complex [36]. Loss of Cdh1 activity has been reported in many cancers, either directly through downregulation [37], or indirectly through loss of the Cdh1 activator PTEN [38]. The accumulation of various APC/C-Cdh1 substrates is also associated with tumor progression and poor prognosis [39].

Here we show that SOCS1 overexpression inhibits in vitro growth of the human melanoma cell lines BLM, MeWo, HT-1080 and UACC-257. In addition, we found that SOCS1 expression inhibits in vivo growth of metastatic BLM melanoma cells. The mechanism of growth suppression involves a block in G1/S and $M$ phases, and SOCS1 association to Cdh1. SOCS1 expression leads to Cdh1 ubiquitination, a marked reduction in Cdh1 levels and concomitant accumulation of the alternative Cdc20. We did not find a significant association between SOCS1 and the latter $\mathrm{APC} / \mathrm{C}$ adaptor. In accordance with the Cdh1/Cdc20 imbalance, SOCS1-BLM arrest concurs with cyclin B1 and securin accumulation and NEK2 degradation. Levels of Aurora A, a well-characterized anaphase substrate of Cdh1 [40], were not altered in BLM-SOCS1 cells.

Taken together, these results implicate SOCS1 in cell cycle progression, and suggest that the SOCS1-dependent balance between $\mathrm{Cdh} 1$ and $\mathrm{Cdc} 20$ controls proliferation of human melanoma. Strategies mimicking SOCS1 effects might therefore be of interest in defining new therapeutic strategies for melanoma treatment. 


\section{Materials and methods}

Mice and cells

Nude mice on the BALB/c background were obtained from Harlan (Barcelona, Spain). Procedures were approved by the CNB Animal Use Ethics Committee in compliance with national and European legislation. Human MeWo, HT-1080 and UACC-257 melanoma cells were obtained from the American Tissue Type Collection (Manassas, VA), and human BLM melanoma cells were kindly donated by Dr. J. Teixidó (CIB/CSIC, Madrid, Spain).

\section{Constructs}

The Flag-SOCS1 sequence was recovered by polymerase chain reaction (PCR) from the $\mathrm{pEF}-\mathrm{FLAG-I} / \mathrm{mSOCS} 1$ construct (from Dr T. Willson, Walter and Eliza Hall Inst., Victoria, Australia) using oligonucleotides 5'NheI-SOCS1 (5-ATGCTAGCATGGCGCGCCAGGACT ACAAG-3) and 3'Sacl-SOCS1 (5-GAGCTCTCAGATCTGGAAgGG GAAGG-3) and cloned into pIRES2Ac-GFPNuc (BD Clontech, Palo Alto, CA) to obtain pIRES2-AcGFP1NucflagSOCS1.

Human Cdh1, Cdc20 and SOCS1 were amplified by PCR using the oligonucleotides listed below and cloned into pECFP-N1/pEYFP-N1 (Cdc20) and into pECFP-C1/pEYFP-C1 (Cdh1 and SOCS1) (Clontech): Cdc20: 5'EcoRI (5'AAGAATTCATGGCACAGTTCGCGTT CGAG3') and $3^{\prime}$ AgeI (5'ACCGGTTTACAGCGGATGCCTTGGTGGAT G3'). Cdh1: 5'EcoRI (5'ATGAATTCAATGGACCAGGAC TATGAGCGG3 $\left.3^{\prime}\right)$ and $3^{\prime} \mathrm{XmaI}\left(5^{\prime} \mathrm{CCCGGG}\right.$ TTACCGGAT CCTGGTGAAGAG3'). SOCS1: 5'EcoRI (5'ATGAATTCA ATGGCGCGCC AGGACTACAAG3') and $3^{\prime} \mathrm{XmaI}\left(5^{\prime} \mathrm{CCC}\right.$ GGGTCAGATCTGGAAGGGGAAGG3').

\section{Cell culture and transfection}

Cells were cultured in Dulbecco's modified Eagle's medium (DMEM) with $10 \%$ fetal calf serum (FCS; both from Invitrogen, Carlsbad, CA). Cells expressing SOCS1 protein were generated after transient transfection $\left(5 \times 10^{6}\right.$ cells $)$, using JetPei reagent (Polyplus, Illkirch, France), with $15 \mu \mathrm{g}$ of pIRES2-AcGFP1Nuc-flagSOCS1 (BLM-SOCS1) or empty pIRES2-AcGFP1Nuc (control), followed by selection in G418 (100 $\mu \mathrm{g} / \mathrm{ml}$; Invitrogen) for in vitro analysis of tumor cell growth. To test the SOCS1-mediated effect on Cdh1 levels, BLM cells $\left(3 \times 10^{5}\right.$ cells $)$ were transiently transfected with different amounts $(1-5 \mu \mathrm{g})$ of pIRES2-AcGFP1Nuc-flagSOCS1 or empty pIRES2-AcGFP1Nuc. To determine Cdh1 ubiquitination, BLM cells were transfected with $4.5 \mu \mathrm{g}$ Cdh1-GFP and $4 \mu \mathrm{g}$ pcDNA3.1-HA-ubiquitin [41] or with $1.5 \mu \mathrm{g}$ of pIRES2-
AcGFP1Nuc-flagSOCS1, alone or with $4.5 \mu \mathrm{g}$ Cdh1-GFP and $4 \mu \mathrm{g}$ pcDNA3.1-HA-ubiquitin.

Tumor cell growth analysis in vitro and in vivo

SOCS1-transfected or control cells were cultured $\left(10^{5}\right.$ cells/plate) in DMEM with $10 \%$ FCS. Cultured cells were harvested daily by trypsinization, and viability assessed by Trypan blue exclusion staining. BALB/c nu/nu mice received intradermal (i.d.) injections in the right flank with BLM-SOCS1 (48 h post-transfection; BLM-SOCS1) or control cells $\left(10^{6}\right.$ cells in $50 \mu \mathrm{l}$ PBS). Tumor growth was measured every 3-4 days using a Vernier precision caliper.

Cell synchronization and drug treatment

\section{Cell synchronization}

We used the double-thymidine release method to synchronize BLM cells in early $\mathrm{S}$ phase. BLM-SOCS1 or control cells were incubated with $2 \mathrm{mM}$ thymidine (SigmaAldrich, St. Louis, MO; $0.4 \times 10^{6}$ cells, $16 \mathrm{~h}, 37^{\circ} \mathrm{C}$ ) washed three times with PBS and released into fresh DMEM $\left(8 \mathrm{~h}, 37^{\circ} \mathrm{C}\right)$. After an additional thymidine treatment $\left(16 \mathrm{~h}, 37^{\circ} \mathrm{C}\right)$, cells were released from early $\mathrm{S}$ phase and harvested by trypsinization at $0,3,5,7$, and $9 \mathrm{~h}$. To measure cell cycle progression, ethanol-fixed samples (15 min, $4{ }^{\circ} \mathrm{C}$ ) were stained with $5 \mu \mathrm{g} / \mathrm{ml}$ propidium iodide (PI; Molecular Probes, Carlsbad, CA) containing 100 $\mu \mathrm{g} / \mathrm{ml}$ RNase A (Sigma-Aldrich; $1 \mathrm{~h}, 37^{\circ} \mathrm{C}$ ) and DNA content analyzed by flow cytometry. To synchronize cells in early M, BLM-SOCS1 and control cells were treated with $100 \mathrm{ng} / \mathrm{ml}$ nocodazole (Sigma-Aldrich; $0.4 \times 10^{6}$ cells, $16 \mathrm{~h}, 37^{\circ} \mathrm{C}$ ), then washed twice with PBS and resuspended in nocodazole-free medium. Cells were harvested by trypsinization at $0,3,5,7$, and $9 \mathrm{~h}$, and DNA content analyzed by flow cytometry after PI staining.

\section{BrdU pulse-chase experiments}

BLM-SOCS1 or control cells were incubated in complete medium with $10 \mathrm{mM}$ BrdU (Sigma-Aldrich; $0.4 \times 10^{6}$ cells, $30 \mathrm{~min}, 37^{\circ} \mathrm{C}$ ) then washed three times with PBS before adding BrdU-free medium. Cells were harvested by trypsinization at $0,3,5,7$, and $9 \mathrm{~h}$, fixed with ice-cold ethanol $\left(30 \mathrm{~min}, 4{ }^{\circ} \mathrm{C}\right)$, incubated in $2 \mathrm{M} \mathrm{HCl}[30 \mathrm{~min}$, room temperature (RT)], and neutralized with $0.1 \mathrm{M}$ sodium tetraborate, $\mathrm{pH} 8.5$. Cells $\left(10^{6} / \mathrm{ml}\right)$ were resuspended in PBS-BT (PBS, $1 \%$ bovine serum albumin [BSA], $0.5 \%$ Tween 20) and incubated with $20 \mu \mathrm{l}$ antiBrdU-FITC antibody (Becton-Dickinson, San Jose, CA; 45 min, RT). After washing with PBS-BT, cells were resuspended in PBS-BT containing $5 \mu \mathrm{g} / \mathrm{ml}$ PI and $100 \mu \mathrm{g} / \mathrm{ml}$ 
RNAse A $\left(1 \mathrm{~h}, 37^{\circ} \mathrm{C}\right)$. Finally, the percentage of BrdUcontaining cells and DNA content were analyzed by flow cytometry.

Proteasome inactivation

BLM-SOCS1 or control cells were incubated in complete medium with $10 \mu \mathrm{M}$ MG132 (Sigma Aldrich, $4 \mathrm{~h}, 37^{\circ} \mathrm{C}$ ) prior to lysis and evaluation by Western blot.

Western blot and antibodies

BLM-SOCS1 and control cells $\left(2 \times 10^{7}\right.$ cells $)$ were lysed, and the lysates were electrophoresed and analyzed in Western blot, as described [42]. Anti-SOCS1 (ab9870), -NEK2 (ab55550) and -securin (DCS 280) antibodies were purchased from Abcam (Cambridge, UK), anti-Cdc20 (H-1759), -p53 (FL-393), -ERK1 (C-16) and -ERK2 (C-14) were from Santa Cruz Biotechnology (Santa Cruz, CA), anti-cyclin D3, -cyclin E, -CDK1-4 and $-\mathrm{p} 19^{\mathrm{ARF}}$ were from BD Transduction Labs (Cell cycle sampler kit I; San Diego, CA), anti-Cdh1 (DH01) was from Thermo Scientific (Fremont, CA), anti-phospho-p53 (16G8) from Cell Signaling (Danvers, MA), anti-cyclin B1 (GNS-1) and -Aurora A from BD Pharmingen (San Diego, CA) and horseradish peroxidase-conjugated secondary antibodies from Dako (Glostrup, Denmark).

To determine Cdh1 ubiquitination, BLM cells transfected with SOCS1 or cotransfected with SOCS1/Cdh1/HAubiquitin or with Cdh1/HA-ubiquitin. Cells were lysed using a detergent buffer $(20 \mathrm{mM}$ triethanolamine $\mathrm{pH} 8.0$, $300 \mathrm{mM} \mathrm{NaCl}, 2 \mathrm{mM}$ EDTA, $20 \%$ glycerol, $1 \%$ digitonin with $10 \mu \mathrm{M}$ sodium orthovanadate, $10 \mu \mathrm{g} / \mathrm{ml}$ leupeptin, and $10 \mu \mathrm{g} / \mathrm{ml}$ aprotinin) $24 \mathrm{~h}$ after transfection, immunoprecipitated using anti-Cdh1 or -HA mAb (HA.11; Covance, Princeton, NJ) and analyzed by Western blot with anti-Cdh1 mAb. In the case of anti-Cdh1 immunoprecipitates, the blot was developed using ExactaCruz E reagent (Santa Cruz Biotechnology) following the manufacturer's protocol.

Immunochemistry

BLM-SOCS1, BLM-Cdh1, BLM-SOCS1/Cdh1 or control cells $\left(3 \times 10^{4}\right.$ cells/well $)$ were plated on collagen-coated coverslips $\left(20 \mu \mathrm{g} / \mathrm{ml}, 1 \mathrm{~h}, 37{ }^{\circ} \mathrm{C}\right.$, Sigma-Aldrich $)$ and cultured $\left(48 \mathrm{~h}, 37^{\circ} \mathrm{C}\right)$. Cells were washed in cold PBS, fixed with $4 \%$ paraformaldehyde (10 min, RT) and permeabilized with $0.2 \%$ Triton X-100 in PBS (10 min, RT). To avoid non-specific binding, cells were treated ( $1 \mathrm{~h}, \mathrm{RT})$ with PBS containing $1 \%$ BSA, $0.1 \%$ goat serum, and $150 \mathrm{mM} \mathrm{NaCl}$. Cells were stained with anti-tubulin (30 min, RT, Sigma-Aldrich), -cyclin B1 (30 min, RT) or -p-histone H3 (Ser 28) antibodies (1 h, RT; Millipore, Bedford, MA), followed by Cy5-goat anti-mouse or -rabbit IgG (30 min, RT; Abcam, Cambridge, UK). After washing, cells were mounted with Vectashield medium containing DAPI (Vector Laboratories Inc., Burlingame, CA). Fluorescence was evaluated on an Olympus IX81 laserscanning confocal microscope.

\section{Measurement of CDK1 activity}

BLM-SOCS1 and control cells $\left(2 \times 10^{7}\right)$ were lysed, and lysates were centrifuged and processed as described [43]. Briefly, we incubated $900 \mu \mathrm{g}$ protein with $3 \mu \mathrm{l}$ anti-cyclin $\mathrm{B} 1 \mathrm{mAb}\left(3 \mathrm{~h}, 4{ }^{\circ} \mathrm{C}\right)$, followed by protein $\mathrm{A}$. For the kinase reaction, immunoprecipitated protein was added to $5 \mu \mathrm{g}$ GST-H1 or cdc25 in kinase buffer. Phosphorylated GST-H1 or cdc25 were detected by SDS-PAGE and autoradiography.

\section{FRET analysis}

FRET was measured by photobleaching as described [44], using BLM cells transiently cotransfected with $0.5 \mu \mathrm{g}$ SOCS1-CFP and $0.5 \mu \mathrm{g}$ Cdh1-YFP, with $0.5 \mu \mathrm{g}$ SOCS1CFP and $0.5 \mu \mathrm{g}$ Cdc20-YFP or with $0.5 \mu \mathrm{g}$ Cdc20-CFP and $0.5 \mu \mathrm{g}$ Cdh1-YFP constructs to assure a 1:1 YFP:CFP ratio. Cells $\left(5 \times 10^{4}\right.$ cells/well $)$ were cultured in coverslip chambers (Nunc) precoated with collagen VI $(20 \mu \mathrm{g} / \mathrm{ml}$, $60 \mathrm{~min}, 37^{\circ} \mathrm{C}$ ), and $48 \mathrm{~h}$ after cDNA transfection, imaged on an Olympus IX81 microscope with a PLAPON 60X03 objective (aperture 1:40) and FV10-ASW 1.6 software. FRET efficiency was calculated from three independent experiments using at least 50 images from each.

Statistical analysis

Statistical analyses were performed using Student's twotailed $t$ test. For FRET analysis, statistics were obtained using Graph Prism 5.0 software (GraphPad). We used nonparametric $t$ test to compare two subject groups and twotailed Mann-Whitney $U$ test for correlation analysis. Data are given as mean $\pm \operatorname{SEM}(* * * p<0.001)$.

\section{Results}

SOCS1 protein expression by human melanoma cells inhibits their in vitro and in vivo growth

We transfected SOCS1 into four human melanoma cell lines that did not express endogenous SOCS1 (BLM, MeWo, HT-1080, UACC-257), and compared their in vitro growth with mock-transfected cells. SOCS1 was cloned into a pIRES2-AcGFP1-Nuc vector to identify cells 
expressing the protein through concomitant nuclear GFP expression. All cells were cultured in complete DMEM, supplemented with G418 in the case of SOCS1 transfected cells, for 7 days and the growth rate was evaluated. Results indicate that SOCS1 expression completely abrogated cell growth (Fig. 1a). Of the lines tested, BLM cells showed complete absence of endogenous SOCS1 in combination with robust SOCS1 expression at $48 \mathrm{~h}$ post-transfection (Fig. 1b). Transiently transfected BLM cells were therefore selected for further experiments.

We tested the effect of SOCS1 expression on in vivo melanoma cell growth. BLM cells expressing SOCS1 (BLM-SOCS1) or mock-transfected (control) were injected i.d. into nude mice, and tumor growth was analyzed over a 25-day period. SOCS1 expression also inhibited in vivo BLM cell growth (Fig. 1c). Whereas $50 \%$ of BLMSOCS1 cell recipients did not generate a solid tumor, the remaining $50 \%$ showed a smaller tumor area than controls (at 25 days, mean $\pm \mathrm{SD}=31.5 \pm 2.8 \mathrm{~mm}^{2}$ vs. $65.1 \pm$
$4.1 \mathrm{~mm}^{2}$, respectively; Online Fig. 1). The data indicate that SOCS1 expression blocks both in vitro and in vivo expansion of melanoma cells.

SOCS1 expression disrupts human melanoma cell cycle transitions at G1/S and G2/M

Since SOCS1 expression blocked proliferation, we assayed the effect of SOCS1 on cell cycle progression. Cell cycle status of BLM-SOCS1 and control cells was evaluated by flow cytometry using PI staining (Fig. 2a, b). We observed a slight but consistent increase in the percentage of BLMSOCS1 cells in G1 phase compared to controls $(60 \% \pm 1.2$ vs. $50 \% \pm 1.3$, respectively), a small decrease in $\mathrm{S}$ phase $(17 \% \pm 1.1$ vs. $21 \% \pm 1.3)$, and a slight reduction in $\mathrm{G} 2 / \mathrm{M}$ cell percentage ( $21 \% \pm 1.1$ vs. $26 \% \pm 1.2)$. In addition, we measured DNA synthesis by flow cytometry analysis of BrdU (5-bromo-2' deoxyuridine) incorporation. Whereas $39 \% \pm 4.2$ of control cells
Fig. 1 SOCS1 expression inhibits human melanoma cell growth. a SOCS1-transfected BLM, MeWo, HT-1080 and UACC-257 or control cells were cultured in complete medium and their growth capacity determined by Trypan blue exclusion at the times indicated. Transfected cells, dark square; control cells, open circle. Data show a representative experiment $(n=3)$. b BLM cells were transiently transfected with pIRES2AcGFP1Nuc-flagSOCS1 construct and SOCS1 expression determined $48 \mathrm{~h}$ post-transfection by following $\mathrm{GFP}^{+}$cells by FACS (left) and by Western-blot analysis using anti-SOCS1 mAb (right). c BLM-SOCS1 and control cells were injected i.d. into nude mice $(n=6)$ and tumor growth determined by monitoring diameter every 3 days. Data show mean tumor area \pm SD. One representative experiment is shown $(n=3)$
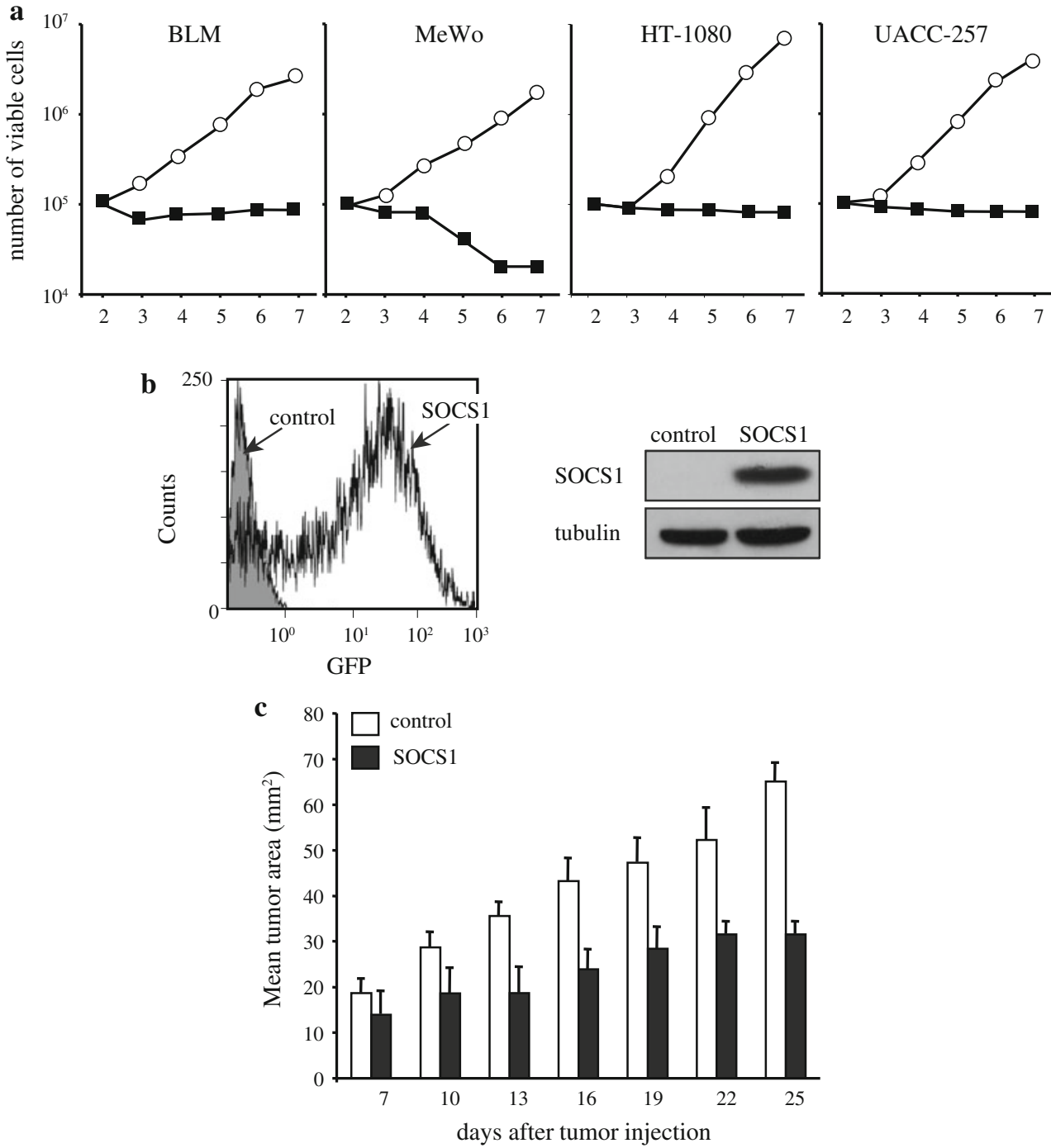
Fig. 2 BLM-SOCS1 cells show cell cycle progression defects. a At $48 \mathrm{~h}$ post-transfection, BLM-SOCS1 and control cells were fixed, PI-stained, and cell cycle analyzed by flow cytometry. A representative experiment is shown $(n=4)$. b The mean percentage \pm SD is shown for cells in each cell cycle phase from experiments in a. c BLM-SOCS1 and control cells were cultured in complete medium with $10 \mathrm{mM}$ BrdU, harvested, fixed, stained with anti-BrdU-FITC mAb and analyzed by flow cytometry. A representative experiment is shown $(n=4)$. d Mean percentage \pm SD of BrdUpositive cells from experiments in $\mathbf{c}$

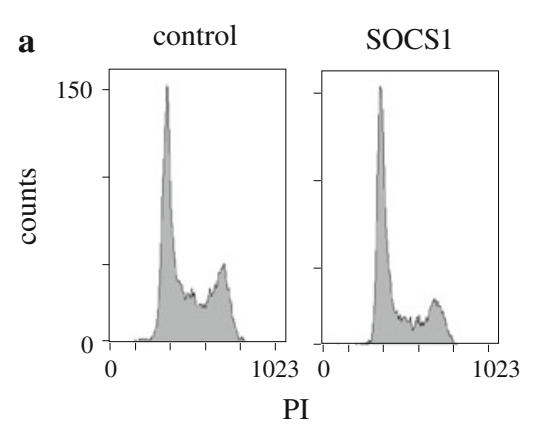

c

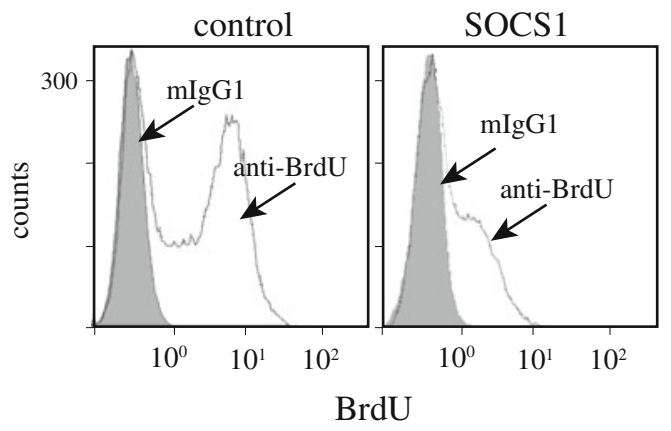

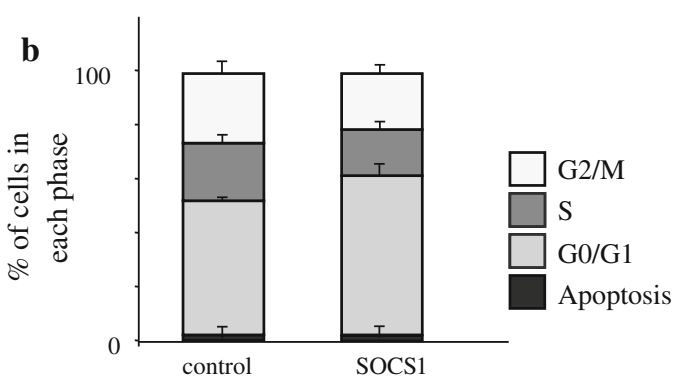

d

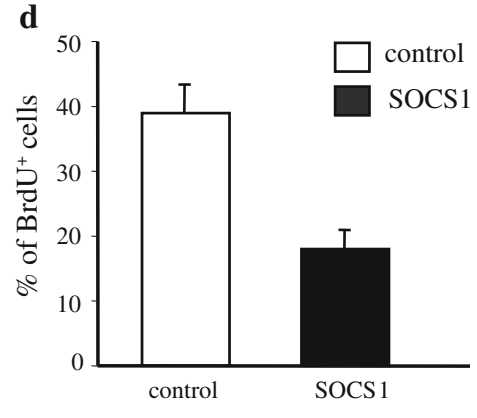

incorporated BrdU, only $19 \% \pm 2.8$ of BLM-SOCS1 cells incorporated BrdU after $30 \mathrm{~min}$. (Fig. 2c, d). These data support previous evidence of a role for SOCS1 in altering G1/S phase progression in tumor cells [13].

Although most BLM-SOCS1 cells accumulated in G1, a small proportion incorporated BrdU, indicating that they progressed through the cell cycle (Fig. 2c). To allow for accumulation in early $\mathrm{S}$ phase, we synchronized BLMSOCS1 and control cells by double thymidine block. Immediately after this blockade, most control cells accumulated in $\mathrm{S}$ phase $(57 \% \pm 3.1$ for controls vs. $26 \% \pm 0.14$ for BLM-SOCS1), whereas a large proportion of BLM-SOCS1 cells were in G1 (49\% 14.1 for BLM-SOCS1 vs. $22 \% \pm 0.39$ for controls) (Fig. 3a, Online Fig. 2). In addition, while control cells resumed a normal cell cycle after release from the thymidine block, the BLM-SOCS1 showed progression through $\mathrm{S}$ but subsequent accumulation in G2/M (Fig. 3a, Online Fig. 2). By $9 \mathrm{~h}$ post-release, approximately half of the control cells had passed through mitosis and were again found in $\mathrm{G} 1 / \mathrm{S}$; the BLM-SOCS1 cells did not progress to G1/S, but remained arrested in mitosis (Online Fig. 2). These results suggest that SOCS1 expression in melanoma cells not only caused a G1/S progression defect, but also altered G2/M phase transition.

To analyze G2/M in detail, we synchronized cells in early $M$ phase using the microtubule polymerization inhibitor nocodazole. In agreement with a slow G1/S transition, nocodazole treatment was less effective for the accumulation of BLM-SOCS1 cells in mitosis when compared to mock transfected controls $(37 \% \pm 3.6$ for BLM-
SOCS1 vs. $80 \% \pm 10.0$ for controls at time 0 h; Fig. 3b, Online Fig. 3). Nonetheless, part of BLM-SOCS1 cells accumulated in mitosis. In contrast to arrested control cells, which resumed mitosis and passed to G1/S after nocodazole release, cell cycle distribution of arrested BLMSOCS1 cells did not change significantly after nocodazole release (Fig. 3b, Online Fig. 3), again indicating a G2/M arrest of BLM-SOCS1 cells.

To exclude interference from the G1/S transition, we analyzed the population of cells that were actively progressing through $\mathrm{S}$ phase. Briefly, BLM-SOCS1 or control cells were incubated in medium with $10 \mathrm{mM}$ BrdU for 30 min, and subsequently chased in BrdU-free medium for the indicated time. In agreement with a defect in $\mathrm{S}$ phase entry, BLM-SOCS1 cells were labeled less efficiently with BrdU (Online Fig. 4). A comparison of BrdU-positive cells however showed an increased accumulation of BLMSOCS1 cells in G2/M after a 9 h chase period $(55 \% \pm 3.7$ vs. $26 \% \pm 4.7$ for controls) (Fig. 3c), confirming the additional defect in G2/M. These data confirm that SOCS1 expression inhibits $\mathrm{G} 1 / \mathrm{S}$ and, as a secondary barrier, blocks the $\mathrm{G} 2 / \mathrm{M}$ transition in human melanoma cells.

SOCS1 expression in human melanoma cells alters protein levels of $\mathrm{G} 1$ phase regulators

To determine the molecular basis of the SOCS1-induced G1/S transition blockade, we analyzed BLM-SOCS1 and control cells by Western blot using mAb specific for several key $\mathrm{G} 1$ regulators, including cyclin $\mathrm{D}$, cyclin $\mathrm{E}$, CDK2, CDK4, p19 ${ }^{\mathrm{ARF}}$ and p53. BLM-SOCS1 cells 
Fig. 3 BLM-SOCS1 cells show defects in G1/S and G2/M transitions. a The G1/S phase transition in BLM-SOCS1 and control cells was analyzed by synchronization, PI staining, and flow cytometry. A representative experiment is shown $(n=3)$. b The $\mathrm{G} 2 / \mathrm{M}$ transition in BLM-SOCS1 and control cells was analyzed after nocodazole synchronization and evaluated as in a. A representative experiment is shown $(n=3)$. c The $\mathrm{S}$ phase transition in BLM-SOCS1 and control cells was analyzed in a BrdU pulse-chase assay, PI and BrdU staining, and flow cytometry evaluation. Mean percentage of cells \pm SD in different cell cycle phases in BrdU-positive cells at $9 \mathrm{~h}$ post-BrdU treatment double-thymidine
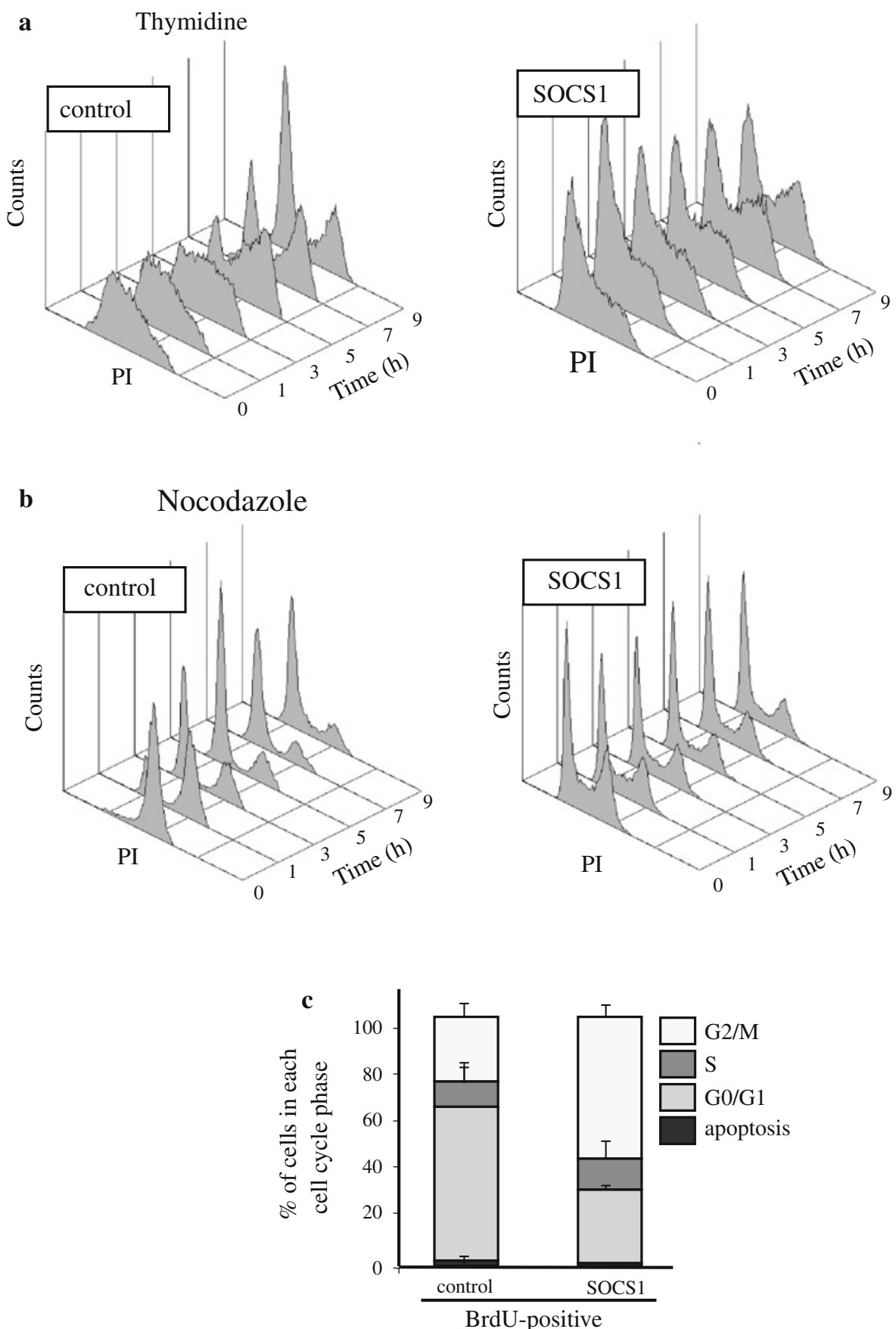

showed a notable decrease in cyclin D and cyclin E levels, and an increase in CDK4 and CDK2 compared to controls (Fig. 4a). SOCS1 expression also led to upregulation of the Mdm2 inhibitor $\mathrm{p} 19^{\mathrm{ARF}}$ and consequently the Mdm2 target p53 [45]; as previously described [24], we detected an increase in both total and phosphorylated (active) p53 (Fig. 4a).

G1/S arrest similar to that observed here was reported in hepatocellular carcinoma cells treated with a JAK inhibitor, and was associated with reduced STAT3 activation [46]. In other studies, however, STAT3 activation is associated with cell cycle arrest [22]. Since SOCS proteins are involved in the regulation of the JAK/STAT pathway [47], we used Western blot to evaluate the effect of SOCS1 on JAK/STAT activation in BLM cells. As indicated for several tumor cell types [48], BLM cells showed constitutively active JAK2/STAT3. SOCS1 expression triggered a marked reduction in p-JAK2 and p-STAT3 (Fig. 4b). Total JAK2 and STAT3 protein levels were nonetheless similar in BLM-SOCS1 and control cells. Our results show that SOCS1 expression in melanoma cells alters cyclin D and cyclin $\mathrm{E}$ levels and increases $\mathrm{p} 19^{\mathrm{ARF}}$ and $\mathrm{p} 53$ 


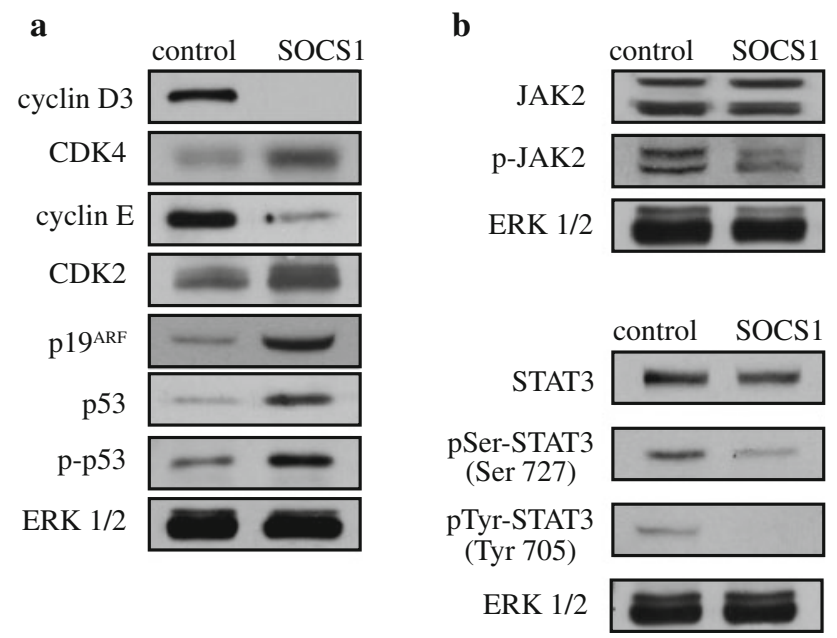

Fig. 4 BLM-SOCS1 cells show defects in key G1 phase regulators. a BLM-SOCS1 and control cells were lysed and analyzed in Western blot with anti-cyclin D3, -CDK4, -cyclin E, -CDK2, -p19 ${ }^{\mathrm{ARF}}$, -p53, and -p-p53 mAb. To control protein loading, the membrane was developed with anti-ERK1/2 antibodies. b Cells as in a were analyzed in Western blot with anti-p-JAK2 mAb (upper) and -pTyr-STAT3 (Tyr 705) or -pSer-STAT3 (Ser 727) mAb (lower). As control, the membrane was developed with anti-JAK2 or -STAT3 mAb

expression, thus inhibiting G1/S transition. In accordance with previous reports, these results show that SOCS1 can regulate an excessive cytokine response, not only by blocking the JAK/STAT pathway directly but also by inducing p53-dependent cell cycle arrest [24].

SOCS1 expression by human melanoma alters protein levels of $\mathrm{M}$ phase regulators

To characterize the SOCS1-induced defects in the G2/M transition, we first evaluated the distribution of the mitotic phases in BLM-SOCS1 and control cells. Cells were stained with DAPI and phosphorylated histone $\mathrm{H} 3(\mathrm{pH} 3)-$ specific antibodies, followed by fluorescence microscopy. In agreement with a G1/S defect, visual inspection showed a marked reduction in the number of $\mathrm{pH} 3$-positive BLMSOCS1 cells compared to controls $(1.4 \% \pm 2.0$ vs. $7.1 \% \pm 1.7$, respectively; Fig. 5a). Mitosis was rescued when BLM cells were cotransfected with SOCS1 and Cdh1 $(3.42 \% \pm 0.5)$. BLM-Cdh1 controls showed $4.8 \% \pm 1.0$ mitotic cells (Fig. 5a). We thus performed a detailed analysis of pH3-positive mitotic cells (Fig. 5b), which showed a reduction of BLM-SOCS1 cells in prophase relative to controls $(44.8 \pm 2.6$ vs. $72.8 \% \pm 1.8$, respectively) and a marked increase in metaphase cells $(43.8 \% \pm 0.4$ vs. $14.9 \% \pm 1.5)$, suggestive of an additional defect in mitotic progression.

$\mathrm{M}$ phase depends on the activation of individual proteins, which are successively degraded as mitosis progresses [49]. To further evaluate the SOCS1-induced blockade of $\mathrm{M}$ phase, we used Western blot to analyze BLM-SOCS1 and control cell lysates with mAb specific for mitotic markers. Compared to controls, BLM-SOCS1 cells showed nearly complete absence of NEK2 (Fig. 5c), which is degraded early in mitosis [36]. In contrast, we observed accumulation of proteins that are normally degraded in the metaphase-to-anaphase transition [49], such as securin and cyclin B1 (Fig. 5c). Proteins levels of Aurora A, a protein kinase degraded late in mitosis [50], showed no alterations (Fig. 5c). To test whether cyclin B1 accumulation altered the activity of its associated kinase CDK1, BLM-SOCS1 and control cell extracts were immunoprecipitated with anti-cyclin $\mathrm{B} 1 \mathrm{mAb}$, and the activity of associated CDK1 was determined in an in vitro kinase assay using cdc 25 and histone $1(\mathrm{H} 1)$ as substrates. The results showed that CDK1 immunoprecipitated from BLM-SOCS1 was more active than that from controls (Fig. 5d). Taken together, these data show that SOCS1 expression in BLM cells results in metaphase arrest.

SOCS1 expression alters $M$ phase protein levels through Cdh1 degradation

Mitotic progression is governed by a large ubiquitin ligase termed APC/C (anaphase-promoting complex) [51]. Ubiquitination by the APC/C labels individual proteins for destruction by the proteasome. To regulate the destruction of individual targets at the appropriate time, Cdh1 and $\mathrm{Cdc} 20$ act as adaptor molecules for the APC/C [52]. To test whether SOCS1 expression alters APC/C adaptors, we assayed Cdh1 and Cdc20 levels in BLM-SOCS1 and control cells, whose lysates were tested in Western blot using anti-Cdc20 and -Cdh1 mAb. SOCS1 expression resulted in increased Cdc20 levels, whereas Cdh1 levels decreased compared to controls (Fig. 6a). Since SOCS itself is an adaptor for ubiquitin ligases [53], the reduction in Cdh1 levels might be a result of proteasomal degradation. To determine if SOCS-dependent Cdh1 reduction requires the proteasome, BLM cells were transiently transfected with SOCS1; after $48 \mathrm{~h}$, cells were left untreated or were treated with the proteasome inhibitor MG132 for $4 \mathrm{~h}$, lysed, and analyzed by Western blot with anti-Cdh1 and -SOCS1 antibodies (Fig. 6b). SOCS1 expression resulted in diminished amounts of Cdh1, confirming the direct correlation between SOCS1 expression and Cdh1 degradation. The loss of Cdh1 protein was prevented by MG132 treatment, indicating that SOCS-dependent ubiquitination targets Cdh 1 for destruction by the proteasome.

To test whether SOCS1 can target Cdh1 for degradation, we evaluated association between SOCS1 and Cdh1 using fluorescence resonance energy transfer (FRET) photobleaching. BLM cells were transiently transfected with Cdh1YFP and SOCS1-CFP, with Cdc20-YFP and SOCS1-CFP 
a

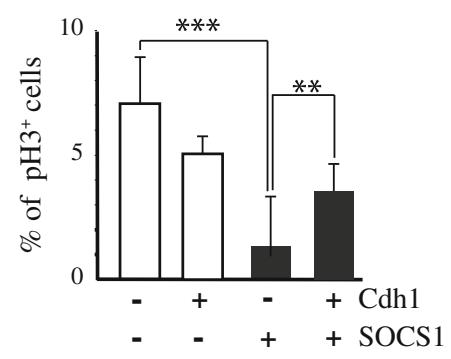

c

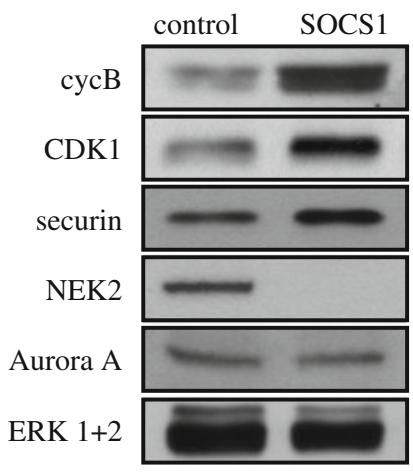

b

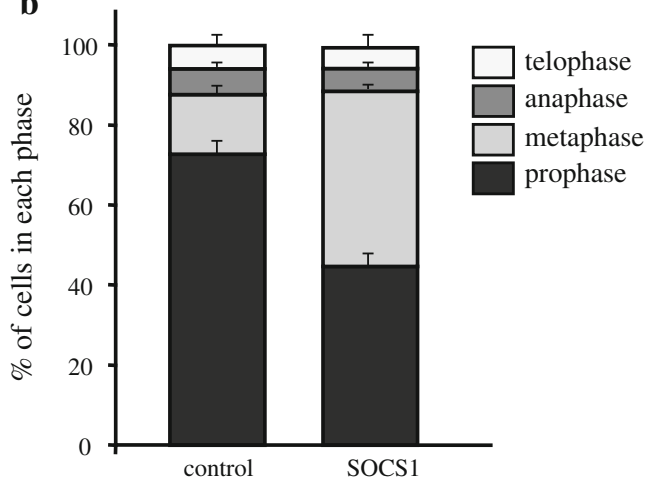

d

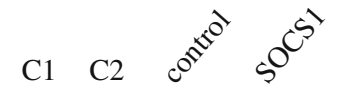

$\operatorname{cdc} 25$

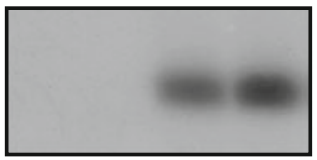

H1

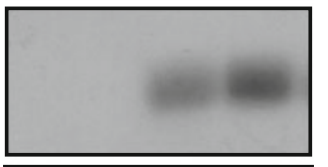

сусB IP

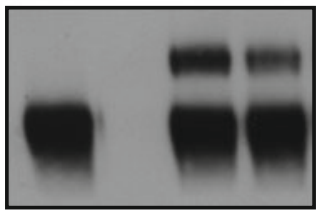

antibodies. As protein loading control, the membrane was developed with anti-ERK1/2 antibodies. d BLM-SOCS 1 and control cells were lysed and immunoprecipitated using anti-CycB1 mAb and the activity of the associated CDK1 evaluated in an in vitro kinase assay using cdc25 or histone $\mathrm{H} 1$ as substrate. As protein loading control, immunoprecipitates were evaluated in Western blot using anti-CycB1 $\mathrm{mAb}$. As specificity controls, cell lysates were incubated with anti$\mathrm{CycB} 1 \mathrm{mAb}(\mathrm{C} 1)$ or with Protein $\mathrm{G}$ alone $(\mathrm{C} 2)$

revealed a laddered pattern typical for protein ubiquitination in cells treated with the proteasome inhibitor (Fig. 6e). We lysed MG132-treated BLM-Cdh1/HA-ubiquitin or BLM-SOCS1/Cdh1/HA-ubiquitin cells and immunoprecipitated the extracts with anti-HA mAb. Western-blot analysis of these immunoprecipitates with anti-Cdh1 mAb verified the presence of ubiquitinated Cdh1 in MG132treated cells, which increased when SOCS1 was coexpressed (Fig. 6f). These results confirmed that, through interaction with SOCS1, Cdh1 is ubiquitinated and degraded by the proteasome.

\section{Discussion}

Several lines of evidence point to a role for SOCS1 as a tumor suppressor. SOCS1/IFN $\gamma$-deficient mice are more 


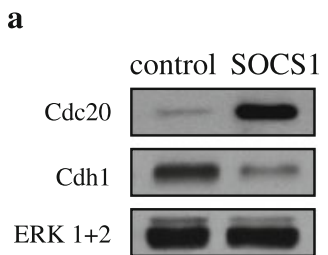

b

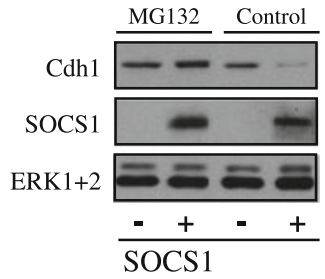

d
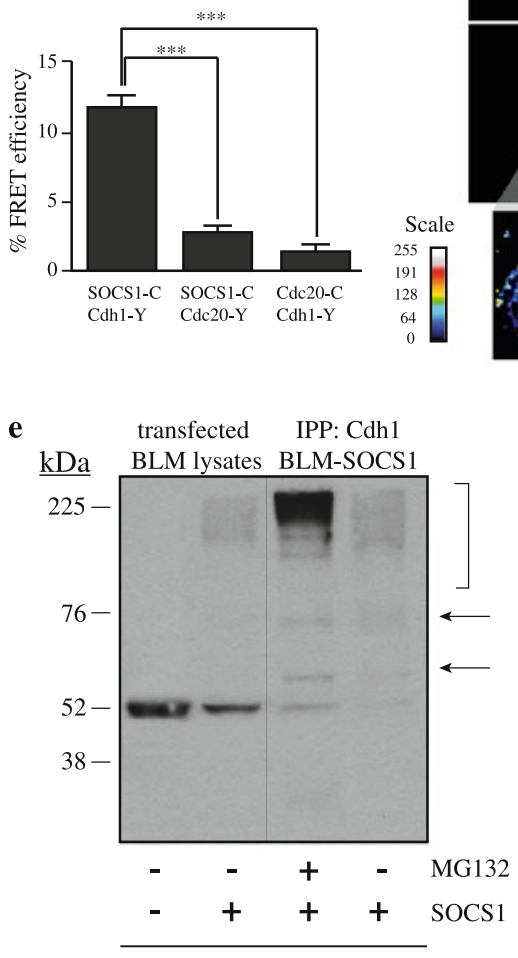

Western blot: Cdh1

c
Cdc20-C/Cdh1-Y SOCS1-C/Cdc20-Y SOCS1-C/Cdh1-Y
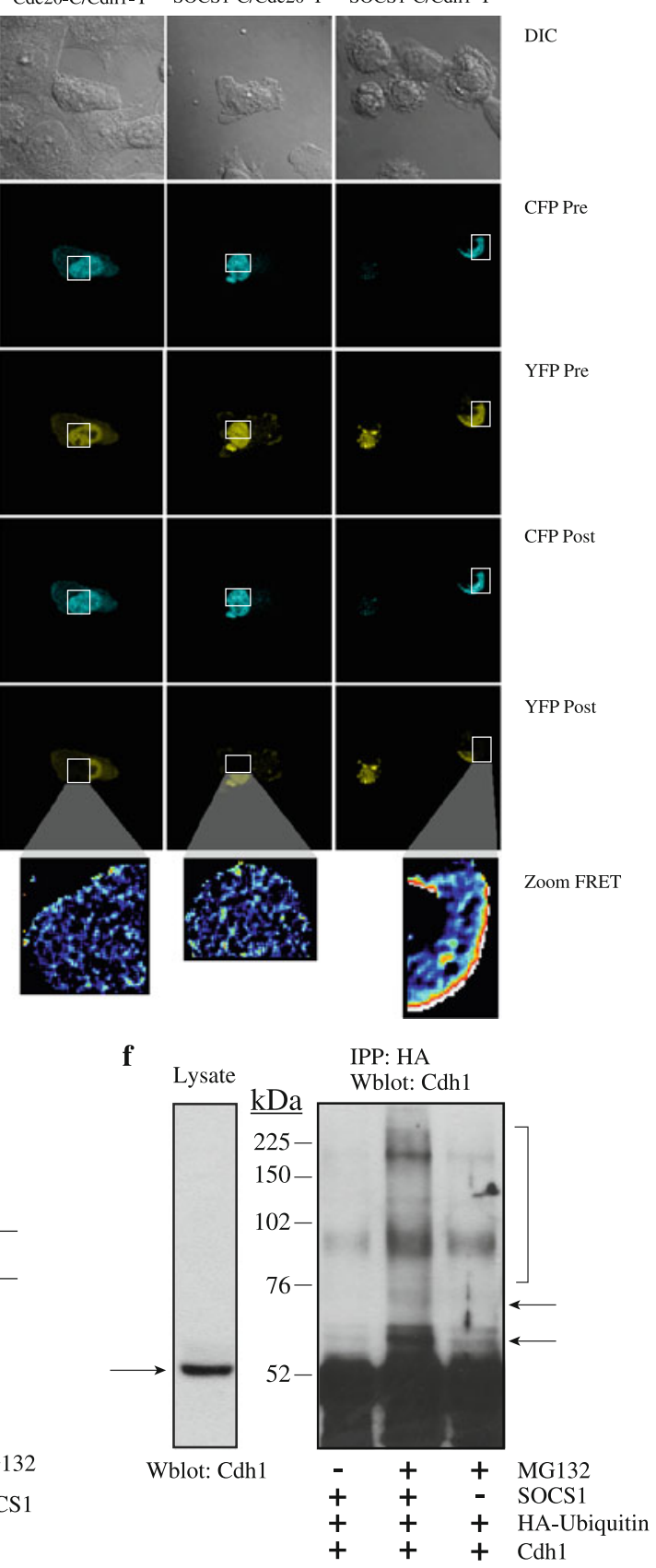

ratio was greater or lower than $\sim 1$ were not included in the analysis. As a negative control, FRET analysis is shown of Cdc20-CFP/Cdh1-YFP complexes by acceptor photobleaching. d FRET efficiency is shown (mean $\pm \mathrm{SEM} ; * * * p<0.001)$. e Untreated or MG132-treated BLMSOCS1 cells were lysed, immunoprecipitated with anti-Cdh1 mAb and analyzed by Western blot using the same mAb. As controls, BLM and BLM-SOCS1 cell lysates were included. Arrows indicate probable Cdh1 mono- and di-ubiquitination; bracket, poly-ubiquitination. $\mathbf{f}$ Untreated and MG132-treated BLM-SOCS1/Cdh1/HA-ubiquitin or BLM-Cdh1/ HA-ubiquitin cells were lysed, immunoprecipitated with anti-HA mAb and analyzed by Western blot with anti-Cdh1 mAb. Arrows indicate probable mono- and di-ubiquitination; bracket, poly-ubiquitination. As control, whole cell lysate of BLM cells was analyzed by Western blot with anti-Cdh1 mAb (left) 
susceptible than normal mice to $\mathrm{T}$ lymphoid leukemia, probably due to the activated state of $\mathrm{T}$ lymphocytes in the absence of SOCS1 [10]. Human tumor cells have developed mechanisms to prevent SOCS1 expression, which endows them with a greater capacity for proliferation and resistance to apoptosis [13]. Loss of SOCS1 results critical for enhanced invasion and angiogenesis of melanoma cells [12], and SOCS1 hypermethylation predicts progression of malignant melanoma [7]. Here we used several SOCS1negative human melanoma cell lines (BLM, MeWo, HT1080 and UACC-257) to show that SOCS1 expression regulates their proliferation both in vitro and in vivo. Although tumor suppression by SOCS1 is well documented, the mechanisms by which SOCS1 prevents cell proliferation remain largely unknown. SOCS1 was initially identified as a negative regulator of cytokine signaling and the JAK2/STAT3 pathway [54, 55]. SOCS1 is expressed as a response to JAK2/STAT3 activation and participates in a negative feedback loop, limiting membrane receptor phosphorylation and JAK2 activity [54, 55]. Although SOCS1 is thought to contribute to tumor suppression by inhibiting a constitutively active JAK2/STAT3 pathway in hepatocellular carcinoma and other carcinomas [6, 11, 13], other studies associate activation of the JAK2/STAT3 pathway with cell cycle arrest $[22,23]$. Thus, although the JAK2/STAT3 pathway appears to have tumor-promoting and -suppressing effects, SOCS1 expression is consistently suppressed in a wide variety of tumors including melanoma [12]; these findings suggest that SOCS1 has a JAK2/ STAT3 pathway-independent role in tumor suppression.

Using a combination of cell synchronization experiments and SOCS1 expression, we show here that SOCS1 inhibits cell cycle progression at the G1/S transition and in mitosis. We observed decreased expression of cyclins D and $\mathrm{E}$, both needed for activation of G1-associated CDK (CDK4/6 and CDK2, respectively). In addition, we found accumulation of $\mathrm{p} 19^{\mathrm{ARF}}$. SOCS1 target proteins JAK2 and STAT3 can promote G1/S progression through expression of cyclins D and E [56]; conversely, JAK2/STAT3 inhibition in tumor cells is linked to G1/S blockade and downregulation of cell cycle molecules such as cyclin D $[57,58]$. In BLM melanoma cells, SOCS1 overexpression also suppressed JAK2/STAT3 activation and correlated with decreased levels of cyclin D3 and E, suggesting that G1/S blockade in our model follows the JAK2/STAT3 pathway. As shown in Cdh1-deficient cells [59], we not only found reduced cyclin E levels reminiscent of a suppressed JAK2/STAT3 pathway but also detected increased levels of the Mdm2 inhibitor p19 ${ }^{\mathrm{ARF}}$ and the Mdm2 target p53 [45] in BLM-SOCS1 cells; a p53-dependent mechanism has been implicated in cell senescence [24] indicating that it might also participate in the G1/S blockade we observed.
Our data show that SOCS1 expression also affected M phase progression, and arrested cells in metaphase. No JAK2/STAT3 pathway involvement has thus far been reported in mitosis. Visual inspection of BLM-SOCS1 cells indicated metaphase blockage, which was subsequently confirmed by analysis of mitotic markers. The main protein complex involved in mitotic progression is the APC/C, which targets substrate proteins for ubiquitination and subsequent destruction by the proteasome [49]. The APC/C undergoes complex regulation through its association with Cdc20 or Cdh1, and through checkpoint-dependent phosphorylation [60]. SOCS1 targets Cdh1 in BLM cells; our FRET analysis showed that SOCS1 specifically associated with Cdh1 but not Cdc20. As a result of this association with SOCS1, Cdh1 was ubiquitinated and degraded by the proteasome. Hence, SOCS1 expression lowers Cdh1 but not Cdc20 levels in BLM cells. Since Cdc20 is a target for the ubiquitin ligase activity of APC/C-Cdh1 complexes [31], SOCS1-mediated Cdh1 degradation might account for Cdc20 accumulation. In accordance with a role for SOCS1 in Cdh1 degradation, cells from mice lacking Cdh1 show proliferative defects and mitotic block reminiscent of BLM-SOCS1 cells, as well as increased Cdc20 levels [59].

Although Cdh1-deficient cells have been analyzed before [59], the exact nature of the cell cycle blockade in these cells is not completely understood. Mitosis is governed by an APC/C-driven feedback loop, in which metaphase-to-anaphase transition is a crucial step [61]. Progression from metaphase to anaphase involves securin degradation, which allows for separase activation, cohesin ring degradation and finally, sister chromatid separation [25]. Correct transition from metaphase to anaphase also requires CDK1 inactivation through degradation of cyclin B1 [26]. In SOCS1-expressing BLM cells, lack of Cdh1 prevents cyclin B1 degradation, resulting in the metaphase arrest observed. This cell cycle transition is blocked following expression of constitutively active CDK1 [61], which maintains inhibition of APC/C-Cdc20 without Cdc20 degradation [35]. These data indicate that in BLMSOCS1 cells, the cyclin B1/CDK1 complex sustains metaphase and prevents APC/C-Cdc20 activation. Simultaneously, the APC/C continues to degrade substrates that do not depend on mitotic checkpoints, such as NEK2 [36, 62]. NEK2 degradation might also interfere with mitosis progression in BLM-SOCS1 cells, since recent reports suggest a role for NEK2 in abolishing MAD2-Cdc20 control of the metaphase checkpoint [63]. Finally, destruction of targets late in mitosis, including Aurora A and Cdc20 itself, again depends on Cdh1 [31, 40]; Cdh1 degradation and metaphase blockade nonetheless prevent BLM-SOCS1 cells from reaching this stage. The combination of markers indicates that Cdh1 is the main SOCS1 target in mitosis and explains why SOCS1 overexpression 
causes accumulation of cells in metaphase. In accordance with these results, we observed that simultaneous expression of Cdh1 overcame the effect of SOCS1 on BLM cells, and mitosis was partially recovered.

Our results show direct interaction between SOCS1 and Cdh1, SOCS1-mediated Cdh1 ubiquitination, and a relationship between SOCS1 expression and Cdh1 downregulation. These findings indicate a role for SOCS1 in Cdh1 degradation. Since SOCS1 expression is partially regulated by JAK2/STAT, SOCS1 provides a link between this pathway and cell cycle progression. Although most of BLM-SOCS1 cells showed G1/S blockade, we detected additional defects in $M$ progression, suggesting that SOCS1 expression establishes two barriers to cell transformation. The methylation status of the SOCS1 gene promoter might explain the divergent effects on cell proliferation observed in different models of JAK2/STAT3 activation. Our data show that SOCS1 has an important function in the control of human melanoma cell cycle progression and indicate that it should be considered in the design of strategies for human melanoma therapy.

Acknowledgments We thank Dr. J. Teixidó for BLM cells, T. Wilson for the pEF-FLAG-I/mSOCS1 construct and J Zalvide for the pcDNA3.1-HA-ubiquitin construct. We also thank C. Bastos and C. Mark for secretarial and editorial assistance, respectively. VP receives a postdoctoral fellowship from the Fundación Sandra Ibarra de Ayuda contra el Cáncer. KvW is financed by a JAE-doc fellowship of the Spanish National Research Council (CSIC). This work was supported by the Fundación Sandra Ibarra de Ayuda contra el Cáncer, the Fundación Genoma España (MEICA), the European Union (Innochem LSHB-CT-2005- 518167; FP7 Integrated Project Masterswitch no. 223404), the Spanish Ministry of Science and Innovation (MICINN; SAF2008-02175; SAF 2011-27370; SAF-2007-63624) and by the Spanish Instituto de Salud Carlos III (ISCIII) RETICS Program (RD08/0075 RIER; RD07/0020).

\section{References}

1. Karpinski P, Myszka A, Ramsey D, Kielan W, Sasiadek MM (2011) Detection of viral DNA sequences in sporadic colorectal cancers in relation to $\mathrm{CpG}$ island methylation and methylator phenotype. Tumour Biol 32(4):653-659. doi:10.1007/s13277011-0165-6

2. Hua D, Hu Y, Wu YY, Cheng ZH, Yu J, Du X, Huang ZH (2011) Quantitative methylation analysis of multiple genes using methylation-sensitive restriction enzyme-based quantitative PCR for the detection of hepatocellular carcinoma. Exp Mol Pathol 91(1):455-460. doi:10.1016/j.yexmp.2011.05.001

3. Sasi W, Jiang WG, Sharma A, Mokbel K (2010) Higher expression levels of SOCS 1,3,4,7 are associated with earlier tumour stage and better clinical outcome in human breast cancer. BMC Cancer 10:178. doi:10.1186/1471-2407-10-178

4. Sutherland LC, Lerman M, Williams GT, Miller BA (2001) LUCA-15 suppresses CD95-mediated apoptosis in Jurkat T cells. Oncogene 20(21):2713-2719. doi:10.1038/sj.onc.1204371

5. Hashimoto M, Ayada T, Kinjyo I, Hiwatashi K, Yoshida H, Okada Y, Kobayashi T, Yoshimura A (2009) Silencing of SOCS1 in macrophages suppresses tumor development by enhancing antitumor inflammation. Cancer Sci 100(4):730-736

6. Yoshikawa H, Matsubara K, Qian GS, Jackson P, Groopman JD, Manning JE, Harris CC, Herman JG (2001) SOCS-1, a negative regulator of the JAK/STAT pathway, is silenced by methylation in human hepatocellular carcinoma and shows growth-suppression activity. Nat Genet 28(1):29-35. doi:10.1038/88225

7. Tanemura A, Terando AM, Sim MS, van Hoesel AQ, de Maat MF, Morton DL, Hoon DS (2009) CpG island methylator phenotype predicts progression of malignant melanoma. Clin Cancer Res 15(5):1801-1807. doi:10.1158/1078-0432.CCR-08-1361

8. Marine JC, Topham DJ, McKay C, Wang D, Parganas E, Stravopodis D, Yoshimura A, Ihle JN (1999) SOCS1 deficiency causes a lymphocyte-dependent perinatal lethality. Cell 98(5):609-616

9. Starr R, Metcalf D, Elefanty AG, Brysha M, Willson TA, Nicola NA, Hilton DJ, Alexander WS (1998) Liver degeneration and lymphoid deficiencies in mice lacking suppressor of cytokine signaling-1. Proc Natl Acad Sci USA 95(24):14395-14399

10. Metcalf D, Mifsud S, Di Rago L, Nicola NA, Hilton DJ, Alexander WS (2002) Polycystic kidneys and chronic inflammatory lesions are the delayed consequences of loss of the suppressor of cytokine signaling-1 (SOCS-1). Proc Natl Acad Sci USA 99(2):943-948. doi:10.1073/pnas.022628499

11. Rottapel R, Ilangumaran S, Neale C, La Rose J, Ho JM, Nguyen MH, Barber D, Dubreuil P, de Sepulveda P (2002) The tumor suppressor activity of SOCS-1. Oncogene 21(28):4351-4362. doi:10.1038/sj.onc.1205537

12. Huang JN, Park I, Ellingson E, Littlepage LE, Pellman D (2001) Activity of the $\mathrm{APC}(\mathrm{Cdh} 1)$ form of the anaphase-promoting complex persists until $\mathrm{S}$ phase and prevents the premature expression of Cdc20p. J Cell Biol 154(1):85-94

13. Flowers LO, Subramaniam PS, Johnson HM (2005) A SOCS-1 peptide mimetic inhibits both constitutive and IL-6 induced activation of STAT3 in prostate cancer cells. Oncogene 24(12):2114-2120. doi:10.1038/sj.onc.1208437

14. Vuong BQ, Arenzana TL, Showalter BM, Losman J, Chen XP, Mostecki J, Banks AS, Limnander A, Fernandez N, Rothman PB (2004) SOCS-1 localizes to the microtubule organizing complexassociated 20S proteasome. Mol Cell Biol 24(20):9092-9101. doi:10.1128/MCB.24.20.9092-9101.2004

15. Zhang JG, Farley A, Nicholson SE, Willson TA, Zugaro LM, Simpson RJ, Moritz RL, Cary D, Richardson R, Hausmann G, Kile BJ, Kent SB, Alexander WS, Metcalf D, Hilton DJ, Nicola NA, Baca M (1999) The conserved SOCS box motif in suppressors of cytokine signaling binds to elongins $\mathrm{B}$ and $\mathrm{C}$ and may couple bound proteins to proteasomal degradation. Proc Natl Acad Sci USA 96(5):2071-2076

16. Ungureanu D, Saharinen P, Junttila I, Hilton DJ, Silvennoinen O (2002) Regulation of Jak2 through the ubiquitin-proteasome pathway involves phosphorylation of Jak2 on Y1007 and interaction with SOCS-1. Mol Cell Biol 22(10):3316-3326

17. Rui L, Yuan M, Frantz D, Shoelson S, White MF (2002) SOCS-1 and SOCS-3 block insulin signaling by ubiquitin-mediated degradation of IRS1 and IRS2. J Biol Chem 277(44):42394-42398. doi:10.1074/jbc.C200444200

18. Nihira K, Ando Y, Yamaguchi T, Kagami Y, Miki Y, Yoshida K (2010) Pim-1 controls NF-kappaB signalling by stabilizing RelA/ p65. Cell Death Differ 17(4):689-698. doi:10.1038/cdd.2009.174

19. Liu E, Cote JF, Vuori K (2003) Negative regulation of FAK signaling by SOCS proteins. EMBO J 22(19):5036-5046. doi: 10.1093/emboj/cdg503

20. Brockman JL, Schroeder MD, Schuler LA (2002) PRL activates the cyclin D1 promoter via the Jak2/Stat pathway. Mol Endocrinol 16(4):774-784

21. Walz C, Crowley BJ, Hudon HE, Gramlich JL, Neuberg DS, Podar K, Griffin JD, Sattler M (2006) Activated Jak2 with the 
V617F point mutation promotes G1/S phase transition. J Biol Chem 281(26):18177-18183. doi:10.1074/jbc.M600064200

22. Moran DM, Mattocks MA, Cahill PA, Koniaris LG, McKillop IH (2008) Interleukin-6 mediates $\mathrm{G}(0) / \mathrm{G}(1)$ growth arrest in hepatocellular carcinoma through a STAT 3-dependent pathway. J Surg Res 147(1):23-33. doi:10.1016/j.jss.2007.04.022

23. Narimatsu M, Nakajima K, Ichiba M, Hirano T (1997) Association of Stat3-dependent transcriptional activation of p19INK4D with IL-6-induced growth arrest. Biochem Biophys Res Commun 238(3):764-768. doi:10.1006/bbrc.1997.7387

24. Calabrese V, Mallette FA, Deschenes-Simard X, Ramanathan S, Gagnon J, Moores A, Ilangumaran S, Ferbeyre G (2009) SOCS1 links cytokine signaling to p53 and senescence. Mol Cell 36(5):754-767. doi:10.1016/j.molcel.2009.09.044

25. Castro A, Bernis C, Vigneron S, Labbe JC, Lorca T (2005) The anaphase-promoting complex: a key factor in the regulation of cell cycle. Oncogene 24(3):314-325. doi:10.1038/sj.onc.1207973

26. Malumbres M, Barbacid M (2009) Cell cycle, CDKs and cancer: a changing paradigm. Nat Rev Cancer 9(3):153-166. doi: $10.1038 /$ nrc2602

27. Morgan DO (1997) Cyclin-dependent kinases: engines, clocks, and microprocessors. Annu Rev Cell Dev Biol 13:261-291. doi: 10.1146/annurev.cellbio.13.1.261

28. Glotzer M, Murray AW, Kirschner MW (1991) Cyclin is degraded by the ubiquitin pathway. Nature 349(6305):132-138. doi:10.1038/349132a0

29. Hershko A, Ganoth D, Pehrson J, Palazzo RE, Cohen LH (1991) Methylated ubiquitin inhibits cyclin degradation in clam embryo extracts. J Biol Chem 266(25):16376-16379

30. Visintin R, Prinz S, Amon A (1997) CDC20 and CDH1: a family of substrate-specific activators of APC-dependent proteolysis. Science 278(5337):460-463

31. Robbins JA, Cross FR (2010) Regulated degradation of the APC coactivator Cdc20. Cell Div 5:23. doi:10.1186/1747-1028-5-23

32. Yu H (2002) Regulation of APC-Cdc20 by the spindle checkpoint. Curr Opin Cell Biol 14(6):706-714

33. Fang G, Yu H, Kirschner MW (1998) The checkpoint protein MAD2 and the mitotic regulator CDC20 form a ternary complex with the anaphase-promoting complex to control anaphase initiation. Genes Dev 12(12):1871-1883

34. Tipton AR, Wang K, Link L, Bellizzi JJ, Huang H, Yen T, Liu ST (2011) BUBR1 and closed MAD2 (C-MAD2) interact directly to assemble a functional mitotic checkpoint complex. J Biol Chem 286(24):21173-21179. doi:10.1074/jbc.M111.238543

35. Listovsky T, Zor A, Laronne A, Brandeis M (2000) Cdk1 is essential for mammalian cyclosome/APC regulation. Exp Cell Res 255(2):184-191. doi:10.1006/excr.1999.4788

36. Hayes MJ, Kimata Y, Wattam SL, Lindon C, Mao G, Yamano H, Fry AM (2006) Early mitotic degradation of Nek2A depends on Cdc20-independent interaction with the APC/C. Nat Cell Biol 8(6):607-614. doi:10.1038/ncb1410

37. Bassermann F, Frescas D, Guardavaccaro D, Busino L, Peschiaroli A, Pagano M (2008) The Cdc14B-Cdh1-Plk1 axis controls the G2 DNA-damage-response checkpoint. Cell 134(2):256-267. doi:10.1016/j.cell.2008.05.043

38. Song MS, Carracedo A, Salmena L, Song SJ, Egia A, Malumbres M, Pandolfi PP (2011) Nuclear PTEN regulates the APC-CDH1 tumor-suppressive complex in a phosphatase-independent manner. Cell 144(2):187-199. doi:10.1016/j.cell. 2010.12.020

39. Carter SL, Eklund AC, Kohane IS, Harris LN, Szallasi Z (2006) A signature of chromosomal instability inferred from gene expression profiles predicts clinical outcome in multiple human cancers. Nat Genet 38(9):1043-1048. doi:10.1038/ng1861

40. Floyd S, Pines J, Lindon C (2008) APC/C Cdh1 targets aurora kinase to control reorganization of the mitotic spindle at anaphase. Curr Biol 18(21):1649-1658. doi:10.1016/j.cub. 2008.09.058

41. Treier M, Staszewski LM, Bohmann D (1994) Ubiquitin-dependent c-Jun degradation in vivo is mediated by the delta domain. Cell 78(5):787-798

42. Vila-Coro AJ, Rodriguez-Frade JM, Martin De Ana A, MorenoOrtiz MC, Martinez AC, Mellado M (1999) The chemokine SDF1alpha triggers CXCR4 receptor dimerization and activates the JAK/STAT pathway. Faseb J 13(13):1699-1710

43. Serrano M, Lin AW, McCurrach ME, Beach D, Lowe SW (1997) Oncogenic ras provokes premature cell senescence associated with accumulation of p53 and p16INK4a. Cell 88(5):593-602

44. Martinez Munoz L, Lucas P, Navarro G, Checa AI, Franco R, Martinez AC, Rodriguez-Frade JM, Mellado M (2009) Dynamic regulation of CXCR1 and CXCR2 homo- and heterodimers. J Immunol 183(11):7337-7346. doi:10.4049/jimmunol.0901802

45. Honda R, Yasuda H (1999) Association of p19(ARF) with Mdm2 inhibits ubiquitin ligase activity of $\mathrm{Mdm} 2$ for tumor suppressor p53. EMBO J 18(1):22-27. doi:10.1093/emboj/18.1.22

46. Fuke H, Shiraki K, Sugimoto K, Tanaka J, Beppu T, Yoneda K, Yamamoto N, Ito K, Masuya M, Takei Y (2007) Jak inhibitor induces $\mathrm{S}$ phase cell-cycle arrest and augments TRAIL-induced apoptosis in human hepatocellular carcinoma cells. Biochem Biophys Res Commun 363(3):738-744. doi:10.1016/j.bbrc. 2007.09.049

47. Croker BA, Kiu H, Nicholson SE (2008) SOCS regulation of the JAK/STAT signalling pathway. Semin Cell Dev Biol 19(4):414-422. doi:10.1016/j.semcdb.2008.07.010

48. Yu H, Pardoll D, Jove R (2009) STATs in cancer inflammation and immunity: a leading role for STAT3. Nat Rev Cancer 9(11):798-809. doi:10.1038/nrc2734

49. Baker DJ, Dawlaty MM, Galardy P, van Deursen JM (2007) Mitotic regulation of the anaphase-promoting complex. Cell Mol Life Sci 64(5):589-600. doi:10.1007/s00018-007-6443-1

50. Lukasiewicz KB, Greenwood TM, Negron VC, Bruzek AK, Salisbury JL, Lingle WL (2011) Control of centrin stability by aurora A. PLoS ONE 6(6):e21291. doi:10.1371/journal.pone. 0021291

51. Qiao X, Zhang L, Gamper AM, Fujita T, Wan Y (2010) APC/CCdh1: from cell cycle to cellular differentiation and genomic integrity. Cell Cycle 9(19):3904-3912

52. Kim S, Yu H (2011) Mutual regulation between the spindle checkpoint and APC/C. Semin Cell Dev Biol. doi:10.1016/j. semcdb.2011.03.008

53. Kile BT, Schulman BA, Alexander WS, Nicola NA, Martin HM, Hilton DJ (2002) The SOCS box: a tale of destruction and degradation. Trends Biochem Sci 27(5):235-241

54. Starr R, Willson TA, Viney EM, Murray LJ, Rayner JR, Jenkins BJ, Gonda TJ, Alexander WS, Metcalf D, Nicola NA, Hilton DJ (1997) A family of cytokine-inducible inhibitors of signalling. Nature 387(6636):917-921. doi:10.1038/43206

55. Naka T, Narazaki M, Hirata M, Matsumoto T, Minamoto S, Aono A, Nishimoto N, Kajita T, Taga T, Yoshizaki K, Akira S, Kishimoto T (1997) Structure and function of a new STAT-induced STAT inhibitor. Nature 387(6636):924-929. doi:10.1038/43219

56. Bharadwaj U, Li M, Chen C, Yao Q (2008) Mesothelin-induced pancreatic cancer cell proliferation involves alteration of cyclin $\mathrm{E}$ via activation of signal transducer and activator of transcription protein 3. Mol Cancer Res 6(11):1755-1765. doi:10.1158/ 1541-7786.MCR-08-0095

57. Leslie K, Lang C, Devgan G, Azare J, Berishaj M, Gerald W, Kim YB, Paz K, Darnell JE, Albanese C, Sakamaki T, Pestell R, Bromberg J (2006) Cyclin D1 is transcriptionally regulated by and required for transformation by activated signal transducer and activator of transcription 3. Cancer Res 66(5):2544-2552. doi: 10.1158/0008-5472.CAN-05-2203 
58. Quintanilla-Martinez L, Davies-Hill T, Fend F, Calzada-Wack J, Sorbara L, Campo E, Jaffe ES, Raffeld M (2003) Sequestration of p27Kip1 protein by cyclin D1 in typical and blastic variants of mantle cell lymphoma (MCL): implications for pathogenesis. Blood 101(8):3181-3187. doi:10.1182/blood2002-01-0263

59. Garcia-Higuera I, Manchado E, Dubus P, Canamero M, Mendez J, Moreno S, Malumbres M (2008) Genomic stability and tumour suppression by the APC/C cofactor Cdh1. Nat Cell Biol 10(7):802-811. doi:10.1038/ncb1742

60. Pesin JA, Orr-Weaver TL (2008) Regulation of APC/C activators in mitosis and meiosis. Annu Rev Cell Dev Biol 24:475-499. doi: 10.1146/annurev.cellbio.041408.115949
61. Ma Y, Yuan X, Wyatt WR, Pomerening JR (2012) Expression of constitutively active CDK1 stabilizes APC-Cdh1 substrates and potentiates premature spindle assembly and checkpoint function in G1 cells. PLoS ONE 7(3):e33835. doi:10.1371/journal. pone. 0033835

62. Hames RS, Wattam SL, Yamano H, Bacchieri R, Fry AM (2001) APC/C-mediated destruction of the centrosomal kinase Nek2A occurs in early mitosis and depends upon a cyclin A-type D-box. EMBO J 20(24):7117-7127. doi:10.1093/emboj/20.24.7117

63. Liu Q, Hirohashi Y, Du X, Greene MI, Wang Q (2010) Nek2 targets the mitotic checkpoint proteins Mad2 and Cdc20: a mechanism for aneuploidy in cancer. Exp Mol Pathol 88(2):225-233. doi:10.1016/j.yexmp.2009.12.004 